\title{
Differentially Expressed Genes by Inhibition of C-terminal Src Kinase by siRNA in Human Vascular Smooth Muscle Cells and Their Association with Blood Pressure
}

\author{
Kyung-Won Hong ${ }^{1 \pi}$, Young-Bin Shin ${ }^{1 \pi}$, Koanhoi \\ $\mathrm{Kim}^{2}$ and Bermseok $\mathrm{Oh}^{1 *}$
}

${ }^{1}$ Department of Biomedical Engineering, School of Medicine, Kyung Hee University, Seoul 130-702, Korea, ${ }^{2}$ Department of Pharmacology, School of Medicine, Pusan National University, Yangsan 626-774, Korea

\begin{abstract}
C-terminal SRC kinase (CSK) is a ubiquitously expressed, cytosolic enzyme that phosphorylates and inactivates several SRC family protein tyrosine kinases. Recent genomewide association studies have implicated CSK in the regulation of blood pressure. The current study aim is to determine the blood pressure association of the genes regulated by CSK down-regulation. The CSK mRNA expression was downregulated in vascular smooth muscle cells using small interfering RNA (siRNA). CSK mRNA levels fell by $90 \%$ in cells that were treated with CSK siRNA; the RNA from these cells was examined by microarray using the Illumina HumanRef-8 v3 platform, which comprises 24,526 reference mRNA probes. On treatment with CSK siRNA, 19 genes were downregulated by more than 2-fold and 13 genes were upregulated by more than 2-fold. Three (CANX, SLC30A7, and HMOX1) of them revealed more than 3 fold differential expression. Interestingly, the HMOX1 SNPs were associated with diastolic blood pressure in the 7551 Koreans using Korea Association REsource data, and the result was supported by the other reports that HMOX1 linked to blood vessel maintenance. Among the remaining 29 differentially expressed genes, seven (SSBP1, CDH2, YWHAE, ME2, PFTK1, G3BP2, and TUFT1) revealed association with both systolic and diastolic blood pressures. The $\mathrm{CDH} 2$ gene was linked to blood pressures. Conclusively, we identified 32 differentially expressed genes which were regulated by CSK reduction, and two (HOMX1 and $\mathrm{CDH} 2)$ of them might influence the blood pressure regulation through CSK pathway.
\end{abstract}

\footnotetext{
"These authors contributed equally to this work

*Corresponding author: E-mail ohbs@khu,ac.kr

Tel +82-2-961-0617, Fax +82-2-961-5515

Accepted 20 June 2011
}

Keywords: CSK, blood pressure, microarray, expression, association analysis

\section{Introduction}

Blood pressure is regulated by many genetic and environmental factors. To identify genes that mediate this regulation, genomewide association studies (GWASs) have been performed using large samples from various ethnicities. The Wellcome Trust Case Control Consortium (WTCCC) (WTCCC, 2007), Amish study (Wang et al., 2009), KORA (Org et al., 2009), KARE (Cho et al., 2009), the Global BPgen consortium (Newton-Cheh et al., 2009), and the CHARGE consortium (Levyt et al., 2009) have conducted GWASs on hypertension and blood pressure, identifying 14 independent loci that govern blood pressure that reached genomewide significance: 6 enzymes, 2 solutes channels, 2 transcription factors, 1 growth factor, 1 cell signaling protein, 1 structural protein, and 1 hypothetical gene (reviewed in Ehret, 2010).

The CSK (C-terminal SRC tyrosine kinase) locus has repeatedly been linked to blood pressure in Korean and European studies (Fig. 1) (Hong et al., 2010a; Levy et al., 2009; Newton-Cheh et al., 2009). CSK is a ubiquitously expressed protein tyrosine kinase that is related structurally to SRC kinases (Nada et al., 1991). The Src family of kinases (SFKs) comprises 9 members (c-src,

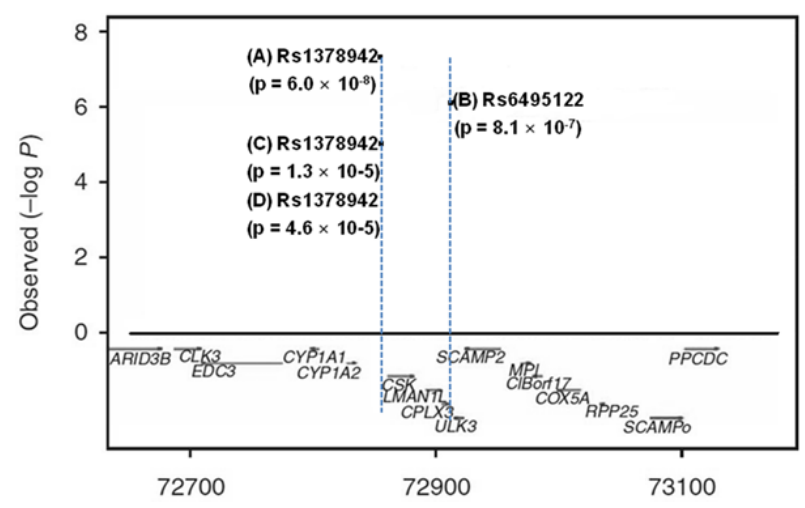

Fig. 1. The highest signals in $15 q 24$ from 3 association studies on blood pressure. A. Signal in Newton-Cheh, et al., 2009. B. Signal in Levy, et al., 2009. C. Signal in Hong, et al., 2010a. D. Signal in Takeuchi, et al., 2010. 
c-yes, fyn, c-fgr, yrk, lck, hck, lyn, and blk) that have similar C-terminal domains that are phosphorylated by CSK (Cheng et al., 1996). SFKs regulate signal transduction through diverse cell surface receptors in many environments (reviewed in Parsons and Parsons, 2004).

CSK-mediated phosphorylation of SFKs at their regulatory tyrosine inhibits their kinase activity. Many reports have documented the importance of CSK in cellular development and the growth control (Chow and Veillette, 1995; Imamoto and Soriano, 1993; Nada et al., 1993). Studies in CSK-deficient mice have shown that CSK regulates embryonic development, particularly the central nervous system (Imamoto and Soriano, 1993). The CSK-deficient mice have also shown that CSK is required both for angiogenic sprouting and vascular remodeling (Duan et al., 2004). In addition, the critical role of C-SRC signaling pathway was reported in angiotensin II-mediated vascular smooth muscle cell proliferation (Sayeski and Ali, 2003).

To understand the CSK function in blood pressure regulation, we reduced CSK mRNA expression in the human vascular smooth muscle cells (VSMCs) using CSK siRNA, examined the expression profile of differentially expressed genes (DEGs) by microarray, and analyzed the genetic association of DEGs with blood pressure traits. DEGs in the VSMCs downregulated by CSK could be candidate genes responsible for the blood pressure regulation through CSK signaling. Among the DEGs, of course there may be genes irrelevant to the blood pressure regulation, but other cellular controls through CSK. Therefore, we performed the association study of DEGs with the blood pressure to determine which DEGs are involved in the blood pressure regulation in this study.

\section{Methods}

\section{Cell culture and reagents}

Human vascular smooth muscle cell lines (CRL-1999 ${ }^{\mathrm{TM}}$ T/G HA-VSMC) were purchased from American Type Culture Collection (ATCC, Manassas, VA). Cell lines were cultured in Kaighn's-modified Ham's F-12K medium (ATCC, Manassas, VA) with $0.05 \mathrm{mg} / \mathrm{ml}$ ascorbic acid, $0.01 \mathrm{mg} / \mathrm{ml}$ insulin, $0.01 \mathrm{mg} / \mathrm{ml}$ transferrin, $10 \mathrm{ng} /$ $\mathrm{ml}$ sodium selenite, $0.03 \mathrm{mg} / \mathrm{ml}$ endothelial cell growth supplement, $10 \mathrm{mM}$ HEPES, $10 \mathrm{mM}$ TES (Sigma, St. Louis, MO), $100 \times$ antibiotic-antimycotic (Gibco, Grand Island, NY), and 10\% fetal bovine serum (Thermo Fisher Scientific, Waltham, MA) in a humidified incubator at $37^{\circ} \mathrm{C}$ and $5 \% \quad \mathrm{CO}_{2}$.

\section{siRNA design and transfection}

An siRNA oligonucleotide that targeted CSK was designed based on the published mRNA sequence of CSK ( $\mathrm{nm}$ number) and synthesized by Genolution Co. Ltd. (Seoul, Korea). Scrambled nontargeting siRNA was also synthesized by Genolution Co. Ltd. (Seoul, Korea). The CSK siRNA sequence is 5'-CTGGCCATCCGGTACAGAA-3'. Twenty-four hours before the transfection, VSMCs were diluted in fresh medium without antibiotics and transferred to 6-well plates. Cells were grown to $80 \%$ confluence and transfected with $150 \mathrm{nmol} / \mathrm{L}$ (final concentration) of siRNA using Lipofectamine RNAiMAX Transfection Reagent (Invitrogen, Carlsbad, CA) per the manufacturer's instructions.

\section{RNA isolation and real-time PCR}

RNA was extracted using RNAiso Plus (Takara, Shiga, Japan). We generated cDNA from $400 \mathrm{ng}$ of total RNA using the PrimeScript ${ }^{\mathrm{TM}}$ RT reagent kit (TaKaRa, Shiga, Japan) used per the manufacturer's manual. CSK expression was analyzed by real-time PCR. One-tenth of the cDNA reaction was added to a final volume of 25 $\mu \mid$ for each real-time PCR reaction using SYBR Green I (TaKaRa, Shiga, Japan). The primers for CSK and GAPDH were (5'-ACCTCAGACGCAGATGGACT/AGCATCACGTCTCCGAACTC-3') and (5'-GCTCTCTGCTCCTCCTGTTC/CAATACGACCAAATCCGTTG-3') respectively (forward/reverse sequence).

Reactions were run on an $\mathrm{ABI}$ Step One real-time PCR system (Applied Biosystems, Foster City, CA) with the following program: 35 cycles of $95^{\circ} \mathrm{C}$ for $40 \mathrm{~s}, 60^{\circ} \mathrm{C}$ for $40 \mathrm{~s}$, and $72^{\circ} \mathrm{C}$ for $40 \mathrm{~s}$. All reactions were performed in triplicate. The significance of differences in relative levels of expression was determined ( $p<0.05$ ) by two-way analysis of variance. The size of the RT-PCR products was analyzed by agarose gel electrophoresis (data not shown).

\section{Labeling and purification of probe for microarray}

Total RNA was amplified and purified using the Ambion Illumina RNA amplification kit (Ambion, Austin, USA) to generate biotinylated cRNA per the manufacturer's instructions. Briefly, $550 \mathrm{ng}$ of total RNA was reverse-transcribed using T7 oligo (dT) primer. Secondstrand cDNA was synthesized, in vitro-transcribed, and labeled with biotin-NTP. After purification, the cRNA was quantified on an ND-1000 spectrophotometer (NanoDrop, Wilmington, USA). 


\section{Hybridization and data export}

Seven hundred fifty nanograms of labeled cRNA was hybridized to each human-8 expression bead array for $16-18 \mathrm{~h}$ at $58^{\circ} \mathrm{C}$, per the manufacturer's instructions (Illumina, Inc., San Diego, USA). Array signals were detected using Amersham fluorolink streptavidin-Cy3 (GE Healthcare Bio-Sciences, Little Chalfont, UK) per the bead array manual. Arrays were scanned on an Illumina Bead Array Reader per the manufacturer's instructions. Array data were exported, processed, and analyzed using Illumina GenomeStudio v2009.2 (Gene Expression Module v1.5.4).

\section{Raw data preparation and statistical analysis}

The quality of hybridization and overall chip performance was monitored by visual inspection of internal quality control checks and raw scanned data. Raw data were extracted using the software that was provided by the manufacturer (Illumina GenomeStudio v2009.2 (Gene Expression Module v1.5.4)). Array data were filtered using a detection $\mathrm{p}$-value $<0.05$ (similar to signal-tonoise) for all samples. Selected gene signal values were log-transformed and normalized by a quantile method. The comparative analysis between test group and control group was evaluated by LPE test using adjusted FDR (false discovery rate) $p$-values. FDR was controlled by adjusting $\mathrm{p}$-values using the Benjamini-Hochberg algorithm.

The gene ontology analysis was performed using PANTHER (http://www.pantherdb.org/panther/ontologies. jsp), using text files containing the Gene ID list and accession number of the Illumina probe ID. Gene Set Enrichment Analysis (GSEA) was performed if an a priori-defined set of genes showed differential patterns with regard to both biological process and molecular function. One-tail Fisher exact test was used to measure the gene enrichment in annotation terms. All data analysis and visualization of differentially expressed genes were conducted using R 2.4.1 (www.r-project.org). The biological ontology-based analysis was performed using the Panther database (http://www.pantherdb.org).

\section{Association study samples}

The KARE subjects and their genotypes have been reported in the original study (Cho et al., 2009). Briefly, 7551 individuals from the KyungGi-Do province, near Seoul, Korea, were recruited for the association analysis between blood pressure and SNP genotypes.

In the original study, blood pressure was measured 3 times with the patient in the supine position. Before the first measurement, the participants rested for 5 minutes, and 3 measurements were taken at least 30 seconds apart. The average of the 3 measurements was used for this study. This study was approved by the International Review Board of the Korea National Institute of Health.

\section{Genotypes and statistical analysis}

KARE DNA samples from the original study were isolated from the peripheral blood of participants and genotyped using the Affymetrix Genomewide Human SNP array 5.0 (Affymetrix, Inc., Santa Clara, CA, USA). The quality controls have been described elsewhere (Cho et al., 2009). Briefly, the accuracy of the genotyping was calculated by Bayesian robust linear modeling using the Mahalanobis distance (BRLMM) genotyping algorithm (Rabbee and Speed, 2006).

Samples that had accuracies below $98 \%$ and a high missing genotype call rate ( $\geq 4 \%$ ), high heterozygosity $(>30 \%)$, or inconsistency in sex were excluded from subsequent analyses. Individuals who had a tumor or were undergoing antihypertensive therapy were excluded. Related individuals whose estimated identity-bystate (IBS) values were high (>0.80) (WTCCC, 2007) were also excluded. The 1956 SNPs that were examined in this study were extracted from the KARE genotype data if they lay within $\pm 5 \mathrm{~kb}$ of the genes and did not deviate from Hardy-Weinberg equilibrium (HWE) ( $p$ $>1 \times 10^{-6}$ ).

The KARE dataset, comprising 351,677 SNPs for 7751 individuals, was merged with that of International HapMap Phase II JPT (Japanese)+HCB (Chinese) panel 2. The genotypes of the KARE individuals were imputed using IMPUTE (Howie et al., 2009) as described (Hong et al., 2010b)

Most statistical analyses were performed using PLINK version 1.07 (http://pngu.mgh.harvard.edu/ purcell/plink/) (Purcell et al., 2007) and SAS (version 9.1; SAS institute Inc., Cary, NC, USA). Systolic blood pressure (SBP) and diastolic blood pressure (DBP) were tested for their association with SNPs by linear regression analysis with an additive model (1-d.f.) after adjustments for area, age, sex, and BMl (Hong et al., 2010a; Hong et al., 2010c).

\section{Results}

\section{CSK inhibition by siRNA}

VSMCs were treated with CSK siRNA for $24 \mathrm{hr}$. By quantitative real-time PCR (qRT-PCR), CSK mRNA levels fell by $90 \%$ compared with controls that were treated 

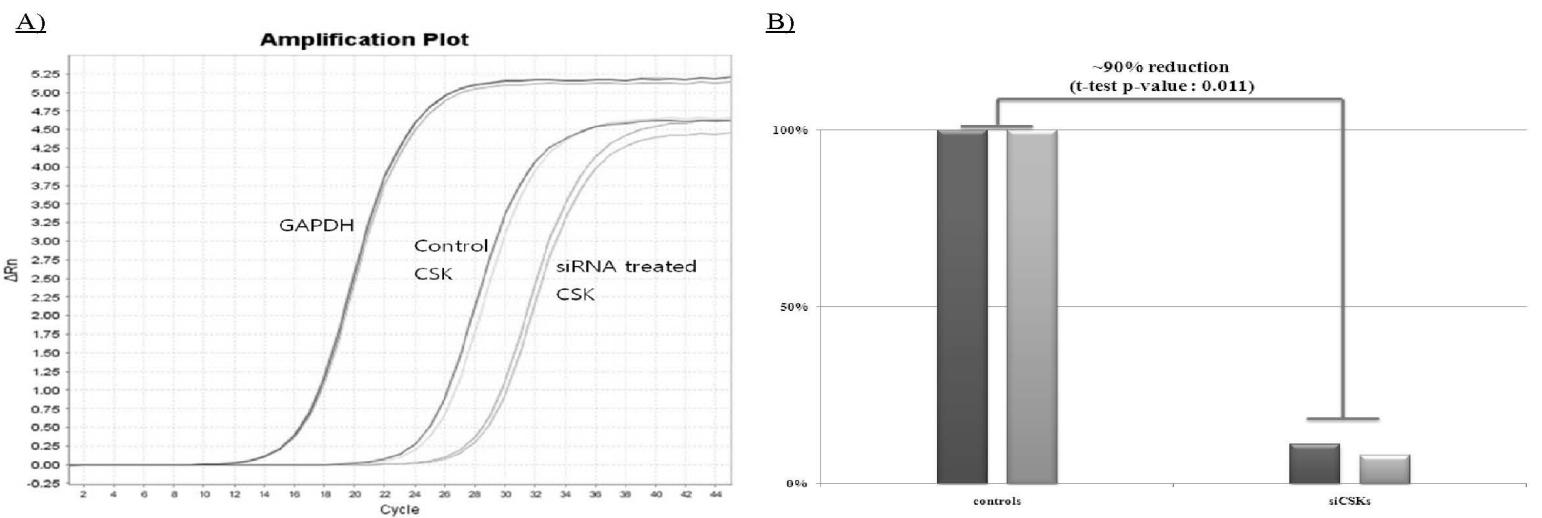

Fig. 2. Real-time PCR for CSK and GAPDH expression. A) Real-time PCR amplication curve in scramble siRNA-treated (Controls) and CSK siRNA-treated samples (siCSK). B) Comparison of CSK and GAPDH expression between siCSK and controls.

with scramble siRNA (Fig. 2).

Four RNA samples-from 2 CSK siRNA-treated (siCSK) and 2 scramble siRNA-treated (control) groups were examined by microarray. CSK mRNA levels declined in siCSK-treated cells by approximately $80 \%$ compared with the controls, mirroring the reductions in VSMCs by qRT-PCR.

\section{Expression microarray profiling}

After false discovery rate (FDR) correction, the expression of 631 genes changed significantly with an adjusted p-value $<0.05$ (288 genes were upregulated and 343 were downregulated), 32 of which changed their expression by more than 2-fold (19 downregulated and 13 upregulated) (Table 1). Notably, a chaperone protein (CANX: calnexin) and a zinc ion transporter (SLC30A7: solute carrier family 30 member 7$)$ decreased their expression by more than 3 -fold $(-3.85 \pm 0.17$ and -3.11 \pm 0.08 , respectively); conversely, an oxidoreductase (HMOX1: heme oxygenase (decycling) 1) increased its expression by greater than 3 -fold $(3.15 \pm 0.44)$.

\section{Gene ontology analysis of DEGs}

We analyzed the ontology of DEGs with regard to biological process (Fig. 3). A gene set enrichment analysis (GSEA) of biological processes was also performed (the results are marked with * over the process in Fig. 3A, $\mathrm{B}$, and $\mathrm{C}$ ). Two biological processes-signal transduction and development-were significantly enriched in upregulated DEGs (Fig. 3B), and 6 categories-signal transduction, phosphate metabolism, immunity and defense, homeostasis, development, and cell cycle-were represented in downregulated DEGs (Fig. 3C).

In the GSEA, one molecular function (signaling mole- cule) was significantly enriched in upregulated DEGs (Fig. 3E), and 4 functions (signaling molecule, receptor, kinase, and ion channel) were preferential in downregulated DEGs (Fig. 3F).

\section{Genetic association analysis}

We analyzed the genetic association of the 32 DEGs (differentially expressed by more than 2-fold) in Table 1 with blood pressure traits in 7551 Koreans. We obtained 1956 SNPs in the DEGs from Korean Association REsource (KARE) data (Table 2) and examined their association with systolic blood pressure (SBP) and diastolic blood pressure (DBP), controlling for cohort, age, sex, and BMI as covariates. The clinical characteristics of the subjects are described in Table 3.

Three hundred ninety-one SNPs from 16 genes were linked to SBP or DBP at $p$-value $<0.05$. Among them, two SNPs (rs2071746 and rs2071748) of HMOX1 gene, the most increased its expression by CSK down regulation, were associated with diastolic blood pressure (Table 4). Seven of less regulated genes $(3>$ Ifold changel $>$ 2) genes (SSBP1, CDH2, YWHAE, ME2, PFTK1, G3BP2, and TUFT1) were correlated with both SBP and DBP, and the minor allele frequencies of their associated SNPs were higher than 0.05 (Table 5).

\section{Discussion}

By microarray, we examined DEGs in siCSK-treated cells. The gene-set enrichment analysis revealed that the signaling molecules were greatly changed in the expression by the CSK reduction. Among the DEGs, thirty-two genes in Table 1 were differentially expressed by more than 2-fold, and calnexin (CANX), a molecular chaperone, experienced the most extensive down- 
106 Genomics \& Informatics Vol. 9(3) 102-113, September 2011

Table 1. Differential expressed genes ( \pm 2-fold) on downregulation of CSK

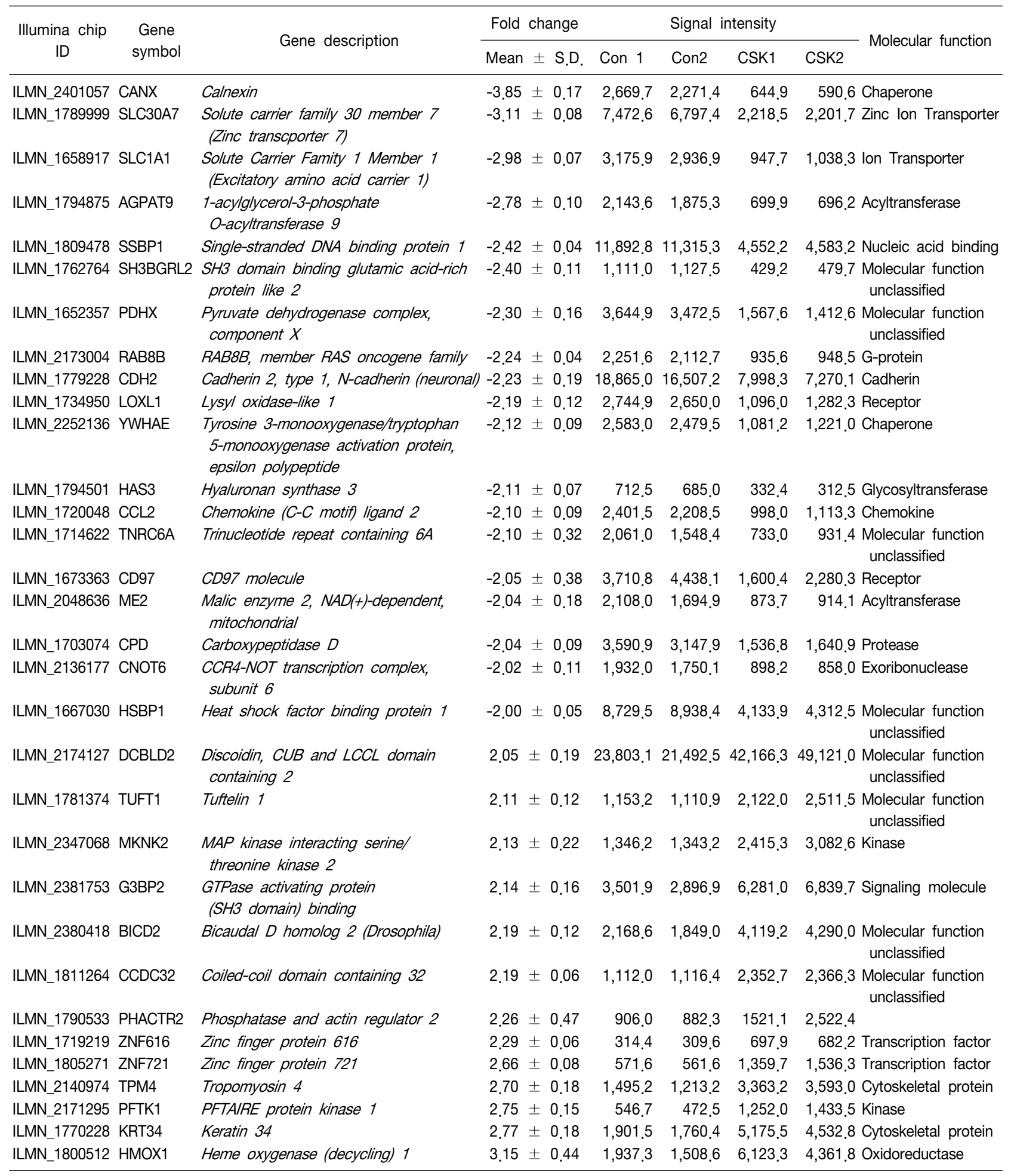

regulation $(-3.85 \pm 0.17$-fold). CANX is a calcium-binding, endoplasmic reticulum (ER)-associated protein that interacts transiently with newly synthesized N-linked gly- coproteins, facilitating protein folding and assembly (Kleizen and Braakman, 2004). Zinc transporter 7 (ZnT7 or SLC30A7) was downregulated by more than 3-fold 


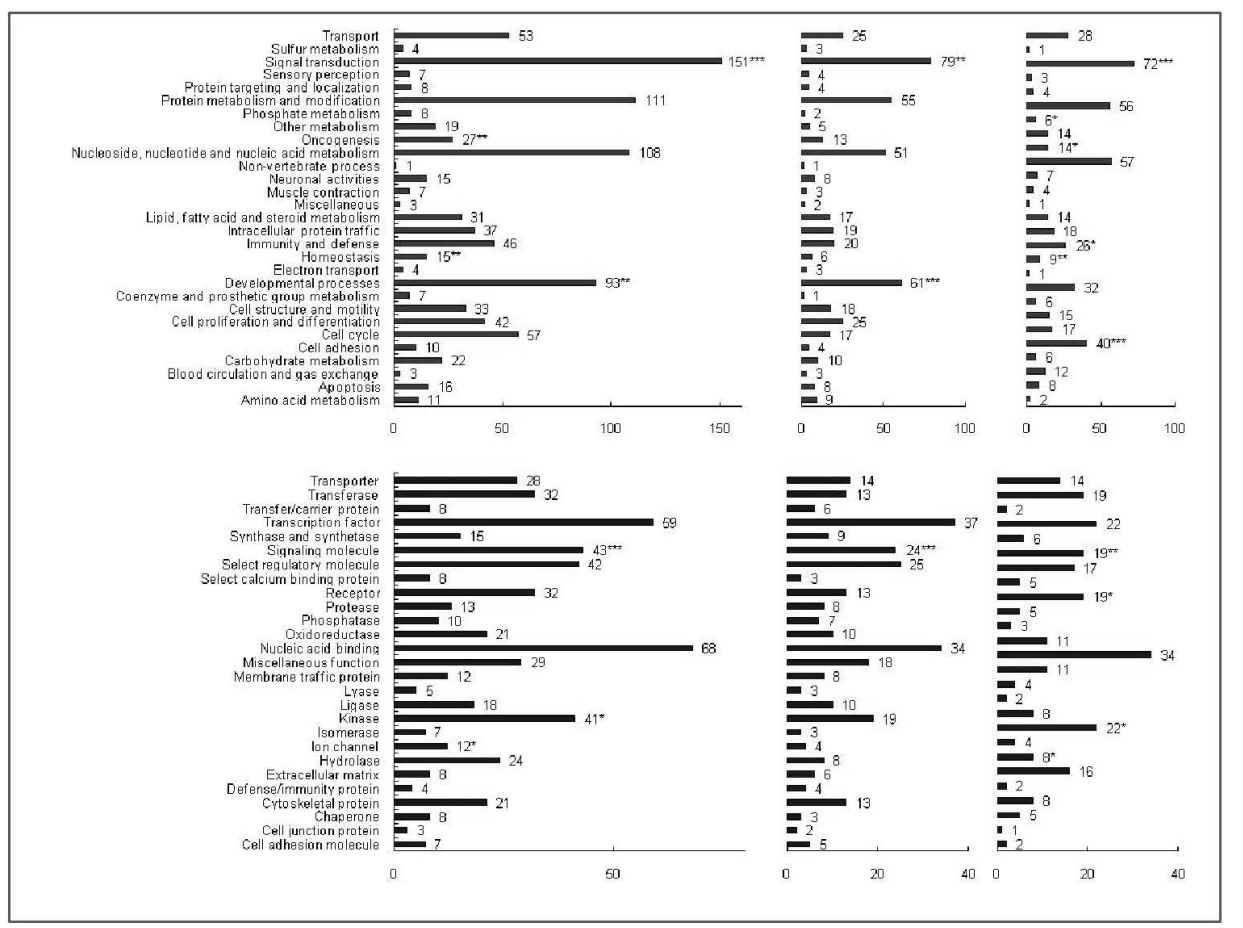

Fig. 3. Gene ontology analysis of biological processes (A, B, C) and molecular function (D, E, F). All differentially expressed genes (DEGs) are described in panels $A$ and $D$; upregulated DEGs are listed in panels $B$ and $E$, and downregulated DEGs are shown in panels $C$ and $F$. Gene set enrichment analysis p-values are denoted as follows: $\mathrm{P}<0.05\left(^{*}\right), \mathrm{P}<0,01$ $\left(^{\star *}\right)$, and $\mathrm{P}<0.001\left(^{(\star \star}\right)$.
(-3.11 \pm 0.08 -fold). ZnT7, a novel member of the zinc transporter $(\mathrm{ZnT})$ family, localizes to the Golgi apparatus and cytoplasmic vesicles, suggesting that ZnT7 mediates zinc transport from the cytoplasm into the Golgi (Kirschke and Huang, 2003). In spite of the great differential expression, the association studies of both CANX and ZnT7/SLC30A7 with blood pressure in Koreans were not significant. Possibly these genes may be involved in the cellular controls through CSK signaling, but irrelevant to the blood pressure regulation.

On the other hand, heme oxygenase 1 (HMOX1), the most significantly upregulated ( $3.15 \pm 0.44$-fold), was associated with diastolic blood pressure, indicating its involvement in the blood pressure regulation through CSK. Heme oxygenase, an essential enzyme in heme catabolism, cleaves heme to form biliverdin, which is subsequently converted to bilirubin and carbon monoxide, a putative neurotransmitter (Yoshida et al., 1988). Human HMOX1 polymorphisms were linked to the risk of coronary artery disease in type II diabetes patients (Chen et al., 2002). Also, HMOX1 overexpression in VSMCs protects them from free radical attack, implicating HMOX1 in the maintenance of blood vessel (Zhang et al., 2002).

Seven gene loci such as SSBP1, CDH2, YWHAE, ME2, TUFT1, C3BP2 and PFTK1 showed the association tendency with both SBP and DBP. Based on a literature search, CDH2 among these genes appears to related to the regulation of blood pressure. $\mathrm{CDH} 2$, also known as neuronal cadherin (N-cadherin), is a classical member of the cadherin superfamily (Reid and Hemperly, 1990). It is a calcium-dependent cell-cell adhesion glycoprotein that comprises 5 extracellular cadherin repeats, a transmembrane region, and a highly conserved cytoplasmic tail (Garcia-Castro et al., 2000). Deletion of $\mathrm{N}$-cadherin from mouse endothelium results in vascular defects, leading to midgestational embryonic lethality, implying that it regulates blood pressure (Luo and Radice, 2005).

The SSBP1 is a single-stranded DNA binding protein, and is a housekeeping gene involved in mitochondrial biogenesis (Tiranti et al., 1995). It is also a subunit of a single-stranded DNA (ssDNA)-binding complex involved in the maintenance of genome stability (Huang et al., 2009). The YWHAE gene belongs to the 14-3-3 family of proteins which mediate signal transduction by binding to phosphoserine-containing proteins (lkeda et al., 2008). The ME2 gene encodes Mitochondrial $\mathrm{NAD}(+)$-dependent malic enzyme (EC 1.1.1.39), and linked to the conversion of amino acid carbon to pyruvate (Loeber et al., 1991). The TUFT1 has been suggested to play an important role during the development and mineralization of enamel (Mao et al., 2001). The G3BP2 gene is a member of GTPase-activating protein $\mathrm{SH} 3$ domain binding protein family and unwound DNA/ DNA, RNA/DNA, and RNA/RNA substrates (Costa et al., 1999). The PFTK1 is a member of the CDC2-related protein kinase family, and involved in the control of the 
Table 2. SNP distribution in significantly differentially expressed genes ( \pm 2 fold) and the number of significant SNPs

\begin{tabular}{|c|c|c|c|c|c|c|c|c|c|c|c|}
\hline \multirow{2}{*}{ Gene symbol } & \multirow{2}{*}{ Chr } & \multicolumn{2}{|c|}{ Gene+-5Kb } & \multicolumn{3}{|c|}{ Number of tested SNPs } & \multicolumn{2}{|l|}{ Mean distance $(b p)$} & \multicolumn{2}{|c|}{ Number of SNPs } & \multirow[b]{2}{*}{$\begin{aligned} & \text { MAF } \\
> & 0.05 \%\end{aligned}$} \\
\hline & & From & to & Total & Genotyped & Imputed & between SNPs & Total & $\begin{array}{c}\text { Any BP } \\
(p<0.05)\end{array}$ & $\begin{array}{l}\text { Both BPs } \\
(p<0.05)\end{array}$ & \\
\hline CANX & 5 & 179053536 & 179085167 & 5 & 0 & 5 & 1895 & 5 & 0 & 0 & 0 \\
\hline SLC30A7 & 1 & 101129266 & 101222582 & 35 & 6 & 29 & 2564 & 35 & 0 & 0 & 0 \\
\hline SLC1A1 & 9 & 4475427 & 4582469 & 97 & 36 & 61 & 1071 & 97 & 0 & 0 & 0 \\
\hline AGPAT9 & 4 & 84671677 & 84751050 & 38 & 13 & 25 & 2100 & 38 & 1 & 1 & 0 \\
\hline SSBP1 & 7 & 141079645 & 141101726 & 14 & 1 & 13 & 1308 & 14 & 14 & 4 & 4 \\
\hline SH3BGRL2 & 6 & 80392719 & 80475088 & 23 & 5 & 18 & 2773 & 23 & 0 & 0 & 0 \\
\hline PDHX & 11 & 34889253 & 34979251 & 115 & 29 & 86 & 753 & 115 & 0 & 0 & 0 \\
\hline RAB8B & 15 & 61263781 & 61352026 & 35 & 10 & 25 & 2442 & 35 & 1 & 0 & 0 \\
\hline $\mathrm{CDH} 2$ & 18 & 23779933 & 24016189 & 224 & 40 & 184 & 1023 & 224 & 88 & 23 & 23 \\
\hline LOXL1 & 15 & 72000842 & 72036531 & 26 & 6 & 20 & 1156 & 26 & 0 & 0 & 0 \\
\hline YWHAE & 17 & 1189584 & 1255306 & 33 & 6 & 27 & 1810 & 33 & 9 & 1 & 1 \\
\hline HAS3 & 16 & 67693944 & 67714071 & 2 & 0 & 2 & 7040 & 2 & 0 & 0 & 0 \\
\hline CCL2 & 17 & 29601409 & 29613333 & 9 & 4 & 5 & 896 & 9 & 0 & 0 & 0 \\
\hline TNRC6A & 16 & 24643550 & 24750048 & 67 & 19 & 48 & 1573 & 67 & 10 & 1 & 0 \\
\hline CD97 & 19 & 14348213 & 14385535 & 2 & 2 & 0 & 7643 & 2 & 2 & 0 & 0 \\
\hline ME2 & 18 & 46654430 & 46735160 & 45 & 12 & 33 & 1778 & 45 & 2 & 1 & 1 \\
\hline CPD & 17 & 25725110 & 25824825 & 32 & 3 & 29 & 3200 & 32 & 0 & 0 & 0 \\
\hline CNOT6 & 5 & 179849023 & 179942959 & 74 & 16 & 58 & 1278 & 74 & 1 & 0 & 0 \\
\hline HSBP1 & 16 & 82394094 & 82409095 & 5 & 3 & 2 & 3585 & 5 & 0 & 0 & 0 \\
\hline DCBLD2 & 3 & 99992504 & 100108223 & 75 & 9 & 66 & 1558 & 75 & 6 & 0 & 0 \\
\hline TUFT1 & 1 & 149774405 & 149827683 & 37 & 11 & 26 & 1358 & 37 & 24 & 19 & 19 \\
\hline MKNK2 & 19 & 1983470 & 2007243 & 3 & 2 & 1 & 4762 & 3 & 0 & 0 & 0 \\
\hline G3BP2 & 4 & 76781977 & 76822691 & 25 & 7 & 18 & 1464 & 25 & 8 & 6 & 4 \\
\hline BICD2 & 9 & 94508466 & 94571904 & 46 & 9 & 37 & 1331 & 46 & 0 & 0 & 0 \\
\hline CCDC32 & 15 & 38627634 & 38647511 & 34 & 10 & 24 & 576 & 34 & 5 & 0 & 0 \\
\hline PHACTR2 & 6 & 143966010 & 144199015 & 173 & 46 & 127 & 1325 & 173 & 13 & 0 & 0 \\
\hline ZNF616 & 19 & 57304465 & 57340003 & 3 & 3 & 0 & 8595 & 3 & 0 & 0 & 0 \\
\hline ZNF721 & 4 & 418779 & 488442 & 26 & 5 & 21 & 2698 & 26 & 0 & 0 & 0 \\
\hline TPM4 & 19 & 16043135 & 16079813 & 13 & 5 & 8 & 915 & 13 & 0 & 0 & 0 \\
\hline PFTK1 & 7 & 90058459 & 90682416 & 618 & 122 & 496 & 1007 & 618 & 205 & 8 & 2 \\
\hline KRT34 & 17 & 36782447 & 36797162 & 7 & 2 & 5 & 1573 & 7 & 0 & 0 & 0 \\
\hline HMOX1 & 22 & 34102060 & 34125207 & 15 & 3 & 12 & 1164 & 15 & 2 & 0 & 0 \\
\hline
\end{tabular}

Table 3. Clinical characteristics of the KARE and replication study subjects

\begin{tabular}{lc}
\hline \multicolumn{1}{c}{ Variables } & $\begin{array}{c}\text { Count/mean } \pm \\
\text { standard deviation }\end{array}$ \\
\hline Number of individuals & 7,751 \\
Gender [men (\%)/women (\%)] & $3,747(50) / 3,804(50)$ \\
Age & $51.44 \pm 8.79$ \\
BMI & $24.4 \pm 3.2$ \\
SBP & $115.65 \pm 17.25$ \\
DBP & $74.21 \pm 11.27$ \\
\hline
\end{tabular}

eukaryotic cell cycle, whose activity is controlled by an associated cyclin (Shu et al., 2007). Even though these genes were found their association with blood pressure in this study, we could not find previous reports about these six genes related to the vascular function as well as blood pressure.

Our study limitation is that none of the 391 associated SNPs passed the multiple correction criteria (Bonferroni $p$-value $<2.6 \times 10^{-5}$ ). Therefore, the further replication study will be necessary and awaiting for the functional analysis validating these findings.

Conclusively, we identified 32 differentially expressed genes which were regulated by CSK reduction, and two (HOMX1 and CDH2) of them might be influence the blood pressure regulation through CSK pathway. 
Table 4. Association results of three most regulated genes (CANX, SLC30A7, and HMOX1)

\begin{tabular}{|c|c|c|c|c|c|c|c|c|c|c|c|c|}
\hline \multirow{2}{*}{ Chr } & \multirow{2}{*}{$\begin{array}{l}\text { SNP } \\
\text { RSID }\end{array}$} & \multirow{2}{*}{$\begin{array}{l}\text { Data } \\
\text { Source }\end{array}$} & \multirow{2}{*}{$\mathrm{BP}$} & & \multirow{2}{*}{$\begin{array}{l}\text { Minor } \\
\text { allele }\end{array}$} & \multirow{2}{*}{ MAF } & \multicolumn{3}{|c|}{ Systolic blood pressure } & \multicolumn{3}{|c|}{ Diastolic blood pressure } \\
\hline & & & & & & & Best & $\mathrm{Se}$ & $\mathrm{p}$-value & Best & $\mathrm{Se}$ & $\mathrm{p}$-value \\
\hline & CANX & Calnexi & & & & & & & & & & \\
\hline 5 & rs 4701197 & I & 179128235 & INTRONIC & $\mathrm{T}$ & 0.29 & 0.19 & 0.29 & 0.52 & 0.02 & 0.19 & 0.93 \\
\hline 5 & rs11744662 & I & 179128706 & INTRONIC & G & 0.45 & 0.01 & 0.26 & 0.96 & -0.09 & 0.18 & 0.63 \\
\hline 5 & rs12374446 & I & 179131143 & INTRONIC & $\mathrm{T}$ & 0.45 & 0.01 & 0.26 & 0.96 & -0.09 & 0.18 & 0.62 \\
\hline 5 & rs7735702 & 1 & 179132612 & INTRONIC & A & 0.15 & -0.23 & 0.36 & 0.51 & -0.17 & 0.24 & 0.49 \\
\hline \multirow[t]{2}{*}{5} & rs6893300 & I & 179135815 & DOWNSTREAM & $A$ & 0.15 & -0.23 & 0.36 & 0.51 & -0.17 & 0.24 & 0.49 \\
\hline & SLC30A7 & Solute & carrier family & 30 member 7 (Zinc transcporter 7) & & & & & & & & \\
\hline 1 & rs3737580 & I & 101360215 & 5PRIME_UTR & $\mathrm{T}$ & 0.17 & 0.14 & 0.35 & 0.68 & 0.05 & 0.24 & 0.82 \\
\hline 1 & rs1074739 & 1 & 101362371 & UPSTREAM & $A$ & 0.08 & -0.55 & 0.47 & 0.24 & -0.36 & 0.32 & 0.26 \\
\hline 1 & rs12569251 & I & 101372040 & INTRONIC & $G$ & 0.07 & -0.52 & 0.51 & 0.31 & -0.21 & 0.34 & 0.54 \\
\hline 1 & rs12040671 & I & 101373328 & INTRONIC & $A$ & 0.43 & -0.35 & 0.28 & 0.21 & -0.10 & 0.19 & 0.61 \\
\hline 1 & rs17408326 & I & 101375854 & INTRONIC & $\mathrm{C}$ & 0.04 & 0.13 & 0.63 & 0.84 & -0.21 & 0.43 & 0.62 \\
\hline 1 & rs10493940 & I & 101377845 & INTRONIC & $\mathrm{G}$ & 0.08 & -0.38 & 0.46 & 0.41 & -0.20 & 0.31 & 0.52 \\
\hline 1 & rs10493939 & I & 101378026 & INTRONIC & G & 0.07 & -0.52 & 0.51 & 0.31 & -0.21 & 0.35 & 0.54 \\
\hline 1 & rs12738779 & 1 & 101378072 & INTRONIC & $\mathrm{G}$ & 0.04 & 0.13 & 0.63 & 0.84 & -0.21 & 0.43 & 0.63 \\
\hline 1 & rs17408457 & 1 & 101385693 & INTRONIC & $\mathrm{G}$ & 0.09 & -0.32 & 0.44 & 0.47 & -0.19 & 0.30 & 0.53 \\
\hline 1 & rs12569174 & $G$ & 101386179 & INTRONIC & C & 0.09 & -0.32 & 0.44 & 0.47 & -0.18 & 0.30 & 0.54 \\
\hline 1 & rs17123521 & $G$ & 101386897 & INTRONIC & C & 0.31 & 0.28 & 0.27 & 0.30 & 0.11 & 0.18 & 0.54 \\
\hline 1 & rs11583674 & 1 & 101396560 & INTRONIC & $\mathrm{G}$ & 0.14 & -0.15 & 0.38 & 0.69 & -0.21 & 0.26 & 0.41 \\
\hline 1 & rs11578366 & I & 101396852 & INTRONIC & $A$ & 0.13 & -0.15 & 0.38 & 0.69 & -0.19 & 0.25 & 0.46 \\
\hline 1 & rs12121879 & I & 101403815 & INTRONIC & $A$ & 0.44 & -0.32 & 0.28 & 0.25 & -0.07 & 0.19 & 0.73 \\
\hline 1 & rs6698798 & 1 & 101407028 & INTRONIC & $T$ & 0.12 & -0.40 & 0.39 & 0.31 & 0.05 & 0.26 & 0.86 \\
\hline 1 & rs11581062 & I & 101407519 & INTRONIC & $\mathrm{G}$ & 0.13 & -0.15 & 0.38 & 0.68 & -0.19 & 0.25 & 0.46 \\
\hline 1 & rs3850453 & I & 101408933 & INTRONIC & C & 0.13 & -0.15 & 0.38 & 0.68 & -0.19 & 0.25 & 0.46 \\
\hline 1 & rs6577219 & 1 & 101415707 & INTRONIC & $G$ & 0.13 & -0.15 & 0.38 & 0.68 & -0.18 & 0.25 & 0.47 \\
\hline 1 & rs11582211 & 1 & 101416871 & INTRONIC & $A$ & 0.12 & -0.14 & 0.39 & 0.73 & -0.18 & 0.27 & 0.50 \\
\hline 1 & rs6577221 & I & 101420406 & INTRONIC & $A$ & 0.09 & -0.31 & 0.44 & 0.48 & -0.17 & 0.30 & 0.57 \\
\hline 1 & rs3903905 & I & 101420957 & INTRONIC & $T$ & 0.13 & -0.18 & 0.38 & 0.62 & -0.20 & 0.25 & 0.43 \\
\hline 1 & rs17448827 & 1 & 101421407 & INTRONIC & $A$ & 0.09 & -0.31 & 0.44 & 0.49 & -0.15 & 0.30 & 0.62 \\
\hline 1 & rs6693339 & $\mathrm{G}$ & 101424431 & INTRONIC & $\mathrm{G}$ & 0.08 & -0.22 & 0.45 & 0.63 & -0.10 & 0.31 & 0.75 \\
\hline 1 & rs6693456 & I & 101424561 & INTRONIC & $\mathrm{G}$ & 0.13 & -0.16 & 0.37 & 0.66 & -0.18 & 0.25 & 0.49 \\
\hline 1 & rs11588568 & $G$ & 101426960 & INTRONIC & $\mathrm{T}$ & 0.04 & 0.08 & 0.62 & 0.90 & -0.25 & 0.42 & 0.55 \\
\hline 1 & rs17610202 & $\mathrm{G}$ & 101429724 & INTRONIC & $\mathrm{G}$ & 0.07 & -0.57 & 0.51 & 0.26 & -0.30 & 0.34 & 0.38 \\
\hline 1 & rs17525507 & 1 & 101430504 & INTRONIC & $A$ & 0.07 & -0.61 & 0.51 & 0.23 & -0.32 & 0.35 & 0.36 \\
\hline 1 & rs7537601 & I & 101435878 & INTRONIC & $A$ & 0.04 & 0.11 & 0.62 & 0.86 & -0.24 & 0.42 & 0.57 \\
\hline 1 & rs12730160 & I & 101438791 & INTRONIC & $A$ & 0.13 & -0.18 & 0.37 & 0.63 & -0.22 & 0.25 & 0.39 \\
\hline 1 & rs3087816 & 1 & 101441775 & 3PRIME_UTR & $\mathrm{C}$ & 0.07 & -0.59 & 0.51 & 0.24 & -0.30 & 0.35 & 0.38 \\
\hline 1 & rs17123572 & I & 101442211 & 3PRIME_UTR & $\mathrm{C}$ & 0.04 & 0.11 & 0.62 & 0.86 & -0.25 & 0.42 & 0.55 \\
\hline 1 & rs17449022 & 1 & 101442367 & 3PRIME_UTR & $G$ & 0.09 & -0.31 & 0.44 & 0.49 & -0.18 & 0.30 & 0.54 \\
\hline 1 & rs10493941 & I & 101445821 & 3PRIME_UTR & $\mathrm{T}$ & 0.04 & 0.11 & 0.62 & 0.86 & -0.25 & 0.42 & 0.55 \\
\hline 1 & rs12726628 & $\mathrm{G}$ & 101446276 & 3PRIME_UTR & $\mathrm{G}$ & 0.04 & -0.27 & 0.64 & 0.67 & -0.54 & 0.43 & 0.21 \\
\hline \multirow[t]{2}{*}{1} & rs6700743 & I & 101447384 & DOWNSTREAM & $\mathrm{T}$ & 0.13 & -0.18 & 0.37 & 0.63 & -0.22 & 0.25 & 0.39 \\
\hline & HMOX1 & heme $c$ & oxygenase (de & ycling) 1 & & & & & & & & \\
\hline 22 & rs2071746 & I & 35776672 & INTRONIC & $\mathrm{T}$ & 0.48 & -0.29 & 0.26 & 0.27 & -0.52 & 0.18 & $3.8 \mathrm{E}-03$ \\
\hline 22 & rs2071747 & I & 35777185 & NON_SYNONYMOUS_CODING & C & 0.04 & 0.86 & 0.64 & 0.18 & 0.04 & 0.44 & 0.92 \\
\hline 22 & rs2071748 & I & 35777618 & INTRONIC & $A$ & 0.45 & -0.37 & 0.26 & 0.16 & -0.44 & 0.18 & 0.01 \\
\hline 22 & rs9306300 & $G$ & 35778278 & INTRONIC & $\mathrm{G}$ & 0.04 & 0.68 & 0.62 & 0.28 & 0.05 & 0.42 & 0.90 \\
\hline 22 & rs5995097 & I & 35778961 & INTRONIC & $\mathrm{C}$ & 0.04 & 0.96 & 0.68 & 0.16 & 0.10 & 0.46 & 0.83 \\
\hline 22 & rs8139532 & 1 & 35779568 & INTRONIC & $A$ & 0.03 & -0.43 & 0.72 & 0.55 & -0.36 & 0.49 & 0.46 \\
\hline 22 & rs8140669 & $G$ & 35779844 & INTRONIC & A & 0.04 & 0.76 & 0.63 & 0.22 & 0.13 & 0.42 & 0.76 \\
\hline 22 & rs9607267 & I & 35781207 & INTRONIC & C & 0.45 & -0.06 & 0.26 & 0.83 & -0.11 & 0.18 & 0.54 \\
\hline
\end{tabular}


110 Genomics \& Informatics Vol. 9(3) 102-113, September 2011

Table 4. Continued

\begin{tabular}{|c|c|c|c|c|c|c|c|c|c|c|c|c|}
\hline \multirow{2}{*}{ Chr } & \multirow{2}{*}{$\begin{array}{l}\text { SNP } \\
\text { RSID }\end{array}$} & \multirow{2}{*}{$\begin{array}{l}\text { Data } \\
\text { Source }\end{array}$} & \multirow{2}{*}{$\mathrm{BP}$} & & \multirow{2}{*}{$\begin{array}{l}\text { Minor } \\
\text { allele }\end{array}$} & \multirow{2}{*}{ MAF } & \multicolumn{3}{|c|}{ Systolic blood pressure } & \multicolumn{3}{|c|}{ Diastolic blood pressure } \\
\hline & & & & & & & Best & $\mathrm{Se}$ & P-value & Best & $\mathrm{Se}$ & P-value \\
\hline 22 & rs6518952 & I & 35782513 & INTRONIC & $\mathrm{T}$ & 0.04 & -0.66 & 0.67 & 0.32 & -0.47 & 0.45 & 0.30 \\
\hline 22 & rs2071749 & $G$ & 35783413 & DOWNSTREAM & A & 0.29 & -0.25 & 0.28 & 0.37 & -0.03 & 0.19 & 0.89 \\
\hline 22 & rs11912889 & 1 & 35783617 & DOWNSTREAM & A & 0.04 & -0.66 & 0.67 & 0.32 & -0.47 & 0.45 & 0.30 \\
\hline 22 & rs5755720 & 1 & 35786873 & DOWNSTREAM & G & 0.43 & 0.02 & 0.26 & 0.93 & -0.07 & 0.18 & 0.70 \\
\hline 22 & rs5995098 & 1 & 35787167 & DOWNSTREAM & G & 0.43 & 0.02 & 0.26 & 0.93 & -0.07 & 0.18 & 0.70 \\
\hline 22 & rs2285112 & I & 35789263 & INTRONIC & G & 0.47 & -0.10 & 0.26 & 0.70 & -0.15 & 0.18 & 0.38 \\
\hline 22 & rs743811 & 1 & 35792974 & DOWNSTREAM & $\mathrm{T}$ & 0.33 & 0.04 & 0.27 & 0.87 & -0.03 & 0.18 & 0.88 \\
\hline
\end{tabular}

Table 5. Significant SNPs that are associated with both systolic and diastolic blood pressure

\begin{tabular}{|c|c|c|c|c|c|c|c|c|c|c|c|c|}
\hline \multirow{2}{*}{ Chr } & \multirow{2}{*}{$\begin{array}{l}\text { SNP } \\
\text { RSID }\end{array}$} & \multirow{2}{*}{$\begin{array}{l}\text { Data } \\
\text { Source }\end{array}$} & \multirow{2}{*}{$\begin{array}{c}\text { Base } \\
\text { Pair }\end{array}$} & \multirow{2}{*}{ Location } & \multirow{2}{*}{$\begin{array}{l}\text { Minor } \\
\text { allele }\end{array}$} & \multirow{2}{*}{ MAF } & \multicolumn{3}{|c|}{ Systolic blood pressure } & \multicolumn{3}{|c|}{ Diastolic blood pressure } \\
\hline & & & & & & & Best & Se & P-value & Best & $\mathrm{Se}$ & $P$-value \\
\hline & SSBP1 & single-stra & ded DNA bindir & protein 1 & & & & & & & & \\
\hline 7 & rs1008318 & 1 & 141433634 & UPSTREAM & G & 0.32 & -0.65 & 0.28 & 0.020 & -0.42 & 0.19 & 0.027 \\
\hline 7 & rs11761832 & । & 141439390 & UPSTREAM & A & 0.32 & -0.64 & 0.28 & 0.021 & -0.42 & 0.19 & 0.027 \\
\hline 7 & rs7784221 & I & 141439404 & UPSTREAM & C & 0.32 & -0.64 & 0.28 & 0.021 & -0.42 & 0.19 & 0.027 \\
\hline \multirow[t]{2}{*}{7} & rs12537498 & I & 141446915 & INTRONIC & A & 0.32 & -0.64 & 0.28 & 0.022 & -0.41 & 0.19 & 0.030 \\
\hline & $\mathrm{CDH} 2$ & cadherin & type 1, N-cad & in (neuronal) & & & & & & & & \\
\hline 18 & rs665781 & I & 25579313 & INTRONIC & $\mathrm{T}$ & 0.36 & -0.62 & 0.26 & 0.020 & -0.41 & 0.18 & 0.022 \\
\hline 18 & rs584936 & I & 25581773 & INTRONIC & A & 0.36 & -0.61 & 0.26 & 0.021 & -0.41 & 0.18 & 0.024 \\
\hline 18 & rs597591 & G & 25582289 & INTRONIC & C & 0.35 & -0.61 & 0.27 & 0.021 & -0.41 & 0.18 & 0.024 \\
\hline 18 & rs614966 & 1 & 25583892 & INTRONIC & A & 0.36 & -0.61 & 0.26 & 0.022 & -0.40 & 0.18 & 0.025 \\
\hline 18 & rs1122356 & I & 25585263 & INTRONIC & G & 0.36 & -0.58 & 0.26 & 0.029 & -0.38 & 0.18 & 0.033 \\
\hline 18 & rs623234 & I & 25589391 & INTRONIC & $\mathrm{T}$ & 0.36 & -0.60 & 0.27 & 0.024 & -0.39 & 0.18 & 0.033 \\
\hline 18 & rs490820 & I & 25596894 & INTRONIC & $T$ & 0.36 & -0.68 & 0.27 & 0.012 & -0.39 & 0.18 & 0.033 \\
\hline 18 & rs673008 & I & 25599702 & INTRONIC & A & 0.37 & -0.67 & 0.27 & 0.012 & -0.37 & 0.18 & 0.043 \\
\hline 18 & rs656642 & I & 25603085 & INTRONIC & G & 0.37 & -0.67 & 0.27 & 0.012 & -0.37 & 0.18 & 0.043 \\
\hline 18 & rs643555 & I & 25603666 & INTRONIC & $\mathrm{T}$ & 0.37 & -0.67 & 0.27 & 0.012 & -0.37 & 0.18 & 0.043 \\
\hline 18 & rs576467 & I & 25603719 & INTRONIC & $\mathrm{T}$ & 0.37 & -0.67 & 0.27 & 0.012 & -0.37 & 0.18 & 0.043 \\
\hline 18 & rs 568575 & I & 25612462 & INTRONIC & C & 0.37 & -0.69 & 0.27 & 0.010 & -0.38 & 0.18 & 0.037 \\
\hline 18 & rs539075 & I & 25613439 & INTRONIC & G & 0.37 & -0.69 & 0.27 & 0.010 & -0.38 & 0.18 & 0.037 \\
\hline 18 & rs533602 & I & 25614034 & INTRONIC & C & 0.37 & -0.71 & 0.27 & 0.008 & -0.39 & 0.18 & 0.033 \\
\hline 18 & rs8087457 & I & 25617625 & INTRONIC & C & 0.35 & -0.76 & 0.28 & 0.006 & -0.45 & 0.19 & 0.017 \\
\hline 18 & rs1234682 & I & 25624066 & INTRONIC & G & 0.40 & -0.64 & 0.26 & 0.015 & -0.35 & 0.18 & 0.049 \\
\hline 18 & rs694943 & 1 & 25626303 & INTRONIC & A & 0.40 & -0.65 & 0.26 & 0.013 & -0.36 & 0.18 & 0.045 \\
\hline 18 & rs500643 & G & 25629299 & INTRONIC & $\mathrm{T}$ & 0.40 & -0.63 & 0.26 & 0.015 & -0.35 & 0.18 & 0.046 \\
\hline 18 & rs8087860 & I & 25673138 & INTRONIC & C & 0.38 & -0.66 & 0.29 & 0.021 & -0.44 & 0.19 & 0.024 \\
\hline 18 & rs1220035 & I & 25692866 & INTRONIC & G & 0.38 & -0.77 & 0.27 & 0.004 & -0.41 & 0.18 & 0.025 \\
\hline 18 & rs1148377 & I & 25693919 & INTRONIC & C & 0.37 & -0.74 & 0.27 & 0.006 & -0.38 & 0.18 & 0.041 \\
\hline 18 & rs1148378 & I & 25694909 & INTRONIC & G & 0.37 & -0.74 & 0.27 & 0.006 & -0.38 & 0.18 & 0.041 \\
\hline \multirow[t]{2}{*}{18} & rs1148379 & I & 25695088 & INTRONIC & C & 0.37 & -0.74 & 0.27 & 0.006 & -0.38 & 0.18 & 0.041 \\
\hline & YWHAE & tyrosine 3 & nonooxygenase, & ptophan 5-monooxyge & ase ac & ctivation & protein, & epsilo & $n$ polypeptid & & & \\
\hline \multirow[t]{2}{*}{17} & rs7210877 & I & 1267472 & INTRONIC & $\mathrm{G}$ & 0.45 & -0.71 & 0.27 & 0.008 & -0.36 & 0.18 & 0.046 \\
\hline & ME2 & malic el & 2, NAD(+)- & ndent, mitochondria & & & & & & & & \\
\hline \multirow[t]{2}{*}{18} & rs661327 & I & 48479444 & DOWNSTREAM & C & 0.10 & -0.88 & 0.42 & 0.037 & -0.62 & 0.29 & 0.031 \\
\hline & PFTK1 & PFTAIRE & otein kinase 1 & & & & & & & & & \\
\hline 7 & rs705349 & $\mathrm{G}$ & 90673308 & INTRONIC & A & 0.50 & -0.67 & 0.25 & 0.008 & -0.46 & 0.17 & 0.007 \\
\hline 7 & rs705352 & I & 90698364 & INTRONIC & $\mathrm{T}$ & 0.50 & 0.61 & 0.26 & 0.017 & 0.43 & 0.17 & 0.014 \\
\hline
\end{tabular}


Table 5. Continued

\begin{tabular}{|c|c|c|c|c|c|c|c|c|c|c|c|c|}
\hline \multirow{2}{*}{ Chr } & \multirow{2}{*}{$\begin{array}{l}\text { SNP } \\
\text { RSID }\end{array}$} & \multirow{2}{*}{$\begin{array}{l}\text { Data } \\
\text { Source }\end{array}$} & \multirow{2}{*}{$\begin{array}{l}\text { Base } \\
\text { Pair }\end{array}$} & \multirow{2}{*}{ Location } & \multirow{2}{*}{$\begin{array}{l}\text { Minor } \\
\text { allele }\end{array}$} & \multirow{2}{*}{ MAF - } & \multicolumn{3}{|c|}{ Systolic blood pressure } & \multicolumn{3}{|c|}{ Diastolic blood pressure } \\
\hline & & & & & & & Best & $\mathrm{Se}$ & $\mathrm{p}$-value & Best & $\mathrm{Se}$ & $\mathrm{p}$-value \\
\hline & G3BP2 & GTPase & activating protein & (SH3 domain) binding & & & & & & & & \\
\hline 4 & rs17000733 & $G$ & 76580894 & INTRONIC & A & 0.08 & 0.97 & 0.46 & 0.034 & 0.75 & 0.31 & 0.015 \\
\hline 4 & rs6531816 & $\mathrm{G}$ & 76581775 & INTRONIC & $\mathrm{C}$ & 0.08 & -1.16 & 0.46 & 0.011 & -0.77 & 0.31 & 0.013 \\
\hline 4 & rs 17000740 & I & 76590608 & INTRONIC & $A$ & 0.08 & 0.91 & 0.46 & 0.048 & 0.73 & 0.31 & 0.019 \\
\hline \multirow[t]{2}{*}{4} & rs3775071 & I & 76593147 & INTRONIC & $A$ & 0.08 & 0.91 & 0.46 & 0.048 & 0.73 & 0.31 & 0.019 \\
\hline & TUFT1 & tuftelin 1 & & & & & & & & & & \\
\hline 1 & rs3811411 & G & 151511268 & DOWNSTREAM & G & 0.50 & 0.66 & 0.25 & 0.008 & 0.42 & 0.17 & 0.014 \\
\hline 1 & rs3790507 & I & 151513247 & DOWNSTREAM & $\mathrm{T}$ & 0.36 & -0.79 & 0.27 & 0.003 & -0.49 & 0.18 & 0.006 \\
\hline 1 & rs11204844 & G & 151515458 & DOWNSTREAM & $\mathrm{G}$ & 0.27 & -0.79 & 0.29 & 0.006 & -0.47 & 0.20 & 0.016 \\
\hline 1 & rs4970957 & 1 & 151517388 & INTRONIC & A & 0.50 & -0.67 & 0.25 & 0.007 & -0.41 & 0.17 & 0.016 \\
\hline 1 & rs6587597 & I & 151520731 & INTRONIC & $A$ & 0.36 & -0.83 & 0.27 & 0.002 & -0.52 & 0.18 & 0.004 \\
\hline 1 & rs17640579 & I & 151521933 & INTRONIC & $\mathrm{G}$ & 0.27 & -0.82 & 0.29 & 0.005 & -0.49 & 0.20 & 0.013 \\
\hline 1 & rs17640598 & I & 151524275 & INTRONIC & G & 0.27 & -0.81 & 0.29 & 0.005 & -0.49 & 0.20 & 0.012 \\
\hline 1 & rs11204848 & I & 151529918 & INTRONIC & C & 0.36 & -0.96 & 0.27 & 0.000 & -0.55 & 0.18 & 0.002 \\
\hline 1 & rs4132646 & I & 151534142 & INTRONIC & A & 0.36 & -0.94 & 0.27 & 0.001 & -0.55 & 0.18 & 0.003 \\
\hline 1 & rs3748610 & I & 151542099 & INTRONIC & $\mathrm{T}$ & 0.41 & 0.51 & 0.26 & 0.048 & 0.38 & 0.18 & 0.033 \\
\hline 1 & rs1539490 & G & 151542626 & INTRONIC & C & 0.41 & 0.53 & 0.26 & 0.041 & 0.40 & 0.18 & 0.025 \\
\hline 1 & rs3790505 & I & 151545057 & INTRONIC & A & 0.28 & -0.60 & 0.28 & 0.036 & -0.39 & 0.19 & 0.044 \\
\hline 1 & rs12751350 & G & 151550673 & INTRONIC & A & 0.41 & 0.52 & 0.26 & 0.045 & 0.37 & 0.18 & 0.037 \\
\hline 1 & rs3748608 & I & 151551320 & INTRONIC & A & 0.41 & 0.53 & 0.26 & 0.042 & 0.38 & 0.18 & 0.031 \\
\hline 1 & rs10494267 & 1 & 151553918 & INTRONIC & $\mathrm{T}$ & 0.41 & 0.54 & 0.26 & 0.037 & 0.39 & 0.18 & 0.027 \\
\hline 1 & rs1891592 & I & 151554503 & 3PRIME_UTR & C & 0.41 & 0.54 & 0.26 & 0.038 & 0.39 & 0.18 & 0.027 \\
\hline 1 & rs11204853 & G & 151557131 & DOWNSTREAM & C & 0.29 & -0.61 & 0.28 & 0.031 & -0.38 & 0.19 & 0.043 \\
\hline 1 & rs4970919 & I & 151557258 & DOWNSTREAM & G & 0.41 & 0.55 & 0.26 & 0.036 & 0.39 & 0.18 & 0.027 \\
\hline 1 & rs1935886 & 1 & 151560153 & DOWNSTREAM & C & 0.41 & 0.57 & 0.26 & 0.030 & 0.41 & 0.18 & 0.020 \\
\hline
\end{tabular}

\section{Acknowledgments}

This work was supported by the Basic Science Research Program through a National Research Foundation of Korea (NRF) grant, funded by the Korean government (MEST) (2010- 0012080).

\section{References}

Chen, Y.H., Lin, S.J., Lin, M.W., Tsai, H.L., Kuo, S.S., Chen, J.W., Charng, M.J., Wu, T. C., Chen, L.C., Ding, Y.A., Pan, W.H., Jou, Y.S., and Chau, L.Y. (2002). Microsatellite polymorphism in promoter of heme oxygenase-1 gene is associated with susceptibility to coronary artery disease in type 2 diabetic patients. Hum. Genet. $111,1-8$.

Cheng, H.C., Bjorge, J.D., Aebersold, R., Fujita, D.J., and Wang, J.H. (1996). Purification of bovine thymus cytosolic C-terminal Src kinase (CSK) and demonstration of differential efficiencies of phosphorylation and inactivation of p56lyn and pp60c-src by CSK. Biochemistry 35, 1187411887.

Cho, Y.S., Go, M.J., Kim, Y.J., Heo, J.Y., Oh, J.H., Ban, H.J., Yoon, D., Lee, M.H., Kim, D.J., Park, M. Cha, S.H., Kim, J.W., Han, B.G., Min, H., Ahn, Y., Park, M.S., Han, H. R., Jang, H.Y., Cho, E.Y., Lee, J.E., Cho, N.H., Shin, C., Park, T., Park, J.W., Lee, J. K., Cardon, L.,
McCarthy, M.I., Lee, J.Y., Oh, B., and Kim, H.L. (2009). A large-scale genome-wide association study of Asian populations uncovers genetic factors influencing eight quantitative traits. Nat. Genet. 41, 527-534.

Chow, L.M., and Veillette, A. (1995). The Src and Csk families of tyrosine protein kinases in hemopoietic cells. Semin Immunol. 7, 207-226.

Costa, M., Ochem, A., Staub, A., and Falaschi, A. (1999). Human DNA helicase VIII: a DNA and RNA helicase corresponding to the G3BP protein, an element of the ras transduction pathway. Nucleic Acids Res, 27, 817-821.

Duan, L.J., Imamoto, A., and Fong, G.H. (2004). Dual roles of the C-terminal Src Kinase (Csk) during developmental vascularization. Blood 103, 1370-1372.

Ehret, G.B. (2010). Genome-wide association studies: contribution of genomics to understanding blood pressure and essential hypertension. Curr. Hypertens. Rep. 12: 17-25.

Garcia-Castro, M.I., Vielmetter, E., and Bronner-Fraser, M. (2000). N-Cadherin, a cell adhesion molecule involved in establishment of embryonic left-right asymmetry. Science 288, 1047-1051.

Hong, K. W., Go, M.J., Jin, H.S., Lim, J. E., Lee, J.Y., Han, B.G., Hwang, S.Y., Lee, S.H., Park, H.K., Cho, Y.S., and Oh, B. (2010a). Genetic variations in ATP2B1, CSK, ARSG and CSMD1 loci are related to blood pressure and/or hypertension in two Korean cohorts. J. Hum. 
Hypertens, 24, 367-372.

Hong, K.W., Lim, J.E., Kim, Y.J., Cho, N.H., Shin, C., and Oh, B. (2010b). KARE genomewide association study of blood pressure using imputed SNPs. Genomics \& Informatics 8, 103-107.

Hong, K. W., Jin, H.S., Lim, J.E., Kim, S., Go, M.J., and Oh, B. (2010c). Recapitulation of two genomewide association studies on blood pressure and essential hypertension in the Korean population. J. Hum. Genet. 55, 336-341.

Huang, L., Yu, Y.Y., Kirschke, C.P., Gertz, E.R., and Lloyd, K.K. (2007). Znt7 (Slc30a7)-deficient mice display reduced body zinc status and body fat accumulation. J. Biol. Chem, 282, 37053-37063.

Imamoto, A., and Soriano, P. (1993). Disruption of the csk gene, encoding a negative regulator of Src family tyrosine kinases, leads to neural tube defects and embryonic lethality in mice. Cell 73, 1117-1124.

Kirschke, C.P., and Huang, L. (2003). ZnT7, a novel mammalian zinc transporter, accumulates zinc in the Golgi apparatus. J. Biol. Chem. 278, 4096-4102.

Kleizen, B., and Braakman, I. (2004). Protein folding and quality control in the endoplasmic reticulum. Curr. Opin. Cell Biol. 16, 343-349.

Levy, D., Ehret, G.B., Rice, K., Verwoert, G.C., Launer, L.J., Dehghan, A., Glazer, N.L., Morrison, A.C., Johnson, A.D., Aspelund, T., Aulchenko, Y., Lumley, T., K?ttgen, A., Vasan, R.S., Rivadeneira, F., Eiriksdottir, G., Guo, X., Arking, D.E., Mitchell, G.F., Mattace-Raso, F.U., Smith, A.V., Taylor, K., Scharpf, R.B., Hwang, S.J., Sijbrands, E. J., Bis, J., Harris, T.B., Ganesh, S. K., O'Donnell, C.J., Hofman, A., Rotter, J.I., Coresh, J., Benjamin, E.J., Uitterlinden, A.G., Heiss, G., Fox, C.S., Witteman, J.C., Boerwinkle, E., Wang, T.J., Gudnason, V., Larson, M.G., Chakravarti, A., Psaty, B.M., and van Duijn, C.M.(2009) Genome-wide association study of blood pressure and hypertension. Nat. Genet. 41, 677-687.

Loeber, G., Infante, A.A., Maurer-Fogy, I., Krystek, E., and Dworkin, M.B. (1991). Human NAD (+)-dependent mitochondrial malic enzyme. cDNA cloning, primary structure, and expression in Escherichia coli. J. Biol. Chem. 266, 3016-3021.

Luo, Y., and Radice, G.L. (2005). N-cadherin acts upstream of VE-cadherin in controlling vascular morphogenesis. $J$. Cell Biol. 169, 29-34.

Mao, Z., Shay, B., Hekmati, M., Fermon, E., Taylor, A., Heikinheimo, K., Lustmann, J., Fisher, L.W., Young, M.F., and Deutsch, D. (2001). The human tuftelin gene: cloning and characterization. Gene 279, 181-196.

Nada, S., Okada, M., MacAuley, A., Cooper, J. A., and Nakagawa, H. (1991). Cloning of a complementary DNA for a protein-tyrosine kinase that specifically phosphorylates a negative regulatory site of p60c-src. Nature 351, 69-72.

Nada, S., Yagi, T., Takeda, H., Tokunaga, T., Nakagawa, H., Ikawa, Y., Okada, M., and Aizawa, S. (1993). Constitutive activation of Src family kinases in mouse embryos that lack Csk. Cell 73, 1125-1135.

Newton-Cheh, C., Johnson, T., Gateva, V., Tobin, M.D.,
Bochud, M., Coin, L., Najjar, S.S., Zhao, J.H., Heath, S.C., Eyheramendy, S., Papadakis, K., Voight, B.F., Scott, L.J., Zhang, F., Farrall, M., Tanaka, T., Wallace, C., Chambers, J.C., Khaw, K.T., Nilsson, P., van der Harst, P., Polidoro, S., Grobbee, D.E., Onland-Moret, N.C., Bots, M.L., Wain, L.V., Elliott, K.S., Teumer, A., Luan, J., Lucas, G., Kuusisto, J., Burton, P.R., Hadley, D., McArdle, W.L.; Wellcome Trust Case Control Consortium, Brown, M., Dominiczak, A., Newhouse, S.J., Samani, N.J., Webster, J., Zeggini, E., Beckmann, J. S., Bergmann, S., Lim, N., Song, K., Vollenweider, P., Waeber, G., Waterworth, D.M., Yuan, X., Groop, L., Orho-Melander, M., Allione, A., Di Gregorio, A., Guarrera, S., Panico, S., Ricceri, F., Romanazzi, V., Sacerdote, C., Vineis, P., Barroso, I., Sandhu, M. S., Luben, R.N., Crawford, G.J., Jousilahti, P., Perola, M., Boehnke, M., Bonnycastle, L. L., Collins, F.S., Jackson, A.U., Mohlke, K.L., Stringham, H.M., Valle, T.T., Willer, C. J., Bergman, R.N., Morken, M.A., Döring, A., Gieger, C., Illig, T., Meitinger, T., Org, E., Pfeufer, A., Wichmann, H.E., Kathiresan, S., Marrugat, J., O'Donnell, C.J., Schwartz, S.M., Siscovick, D.S., Subirana, I., Freimer, N.B. Hartikainen, A.L., McCarthy, M.I., O'Reilly, P.F., Peltonen, L., Pouta, A., de Jong, P.E., Snieder, H., van Gilst, W.H., Clarke, R., Goel, A., Hamsten, A., Peden, J.F., Seedorf, U., Syvänen, A.C., Tognoni, G., Lakatta, E.G., Sanna, S., Scheet, P., Schlessinger, D., Scuteri, A., Dörr, M., Ernst, F., Felix, S.B., Homuth, G., Lorbeer, R., Reffelmann, T., Rettig, R., Völker, U., Galan, P., Gut, I.G., Hercberg, S., Lathrop, G.M., Zelenika, D., Deloukas, P., Soranzo, N., Williams, F.M., Zhai, G., Salomaa, V., Laakso, M., Elosua, R., Forouhi, N.G., Völzke, H., Uiterwaal, C.S., van der Schouw, Y.T., Numans, M.E., Matullo, G., Navis, G., Berglund, G., Bingham, S.A., Kooner, J.S., Connell, J.M., Bandinelli, S., Ferrucci, L., Watkins, H., Spector, T.D., Tuomilehto, J., Altshuler, D., Strachan, D.P., Laan, M., Meneton, P., Wareham, N.J., Uda, M., Jarvelin, M.R., Mooser, V., Melander, O., Loos, R.J., Elliott, P., Abecasis, G.R., Caulfield, M., and Munroe, P.B. (2009) Genome-wide association study identifies eight loci associated with blood pressure. Nat. Genet. 41, 666-676.

Org, E., Eyheramendy, S., Juhanson, P., Gieger, C.,

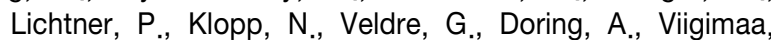
M. and Sober, S. (2009). Genome-wide scan identifies $\mathrm{CDH} 13$ as a novel susceptibility locus contributing to blood pressure determination in two European populations. Hum. Mol. Genet. 18, 2288-2296.

Parsons, S.J., and Parsons, J.T. (2004). Src family kinases, key regulators of signal transduction. Oncogene 23, 7906-7909.Rabbee, N., and Speed, T. P. (2006). A genotype calling algorithm for affymetrix SNP arrays. Bioinformatics 22, 7-12.

Reid, R.A., and Hemperly, J.J. (1990). Human N-cadherin: nucleotide and deduced amino acid sequence. Nucleic Acids Res. 18, 5896.

Takeuchi, F., Isono, M., Katsuya, T., Yamamoto, K., Yokota, M., Sugiyama, T., Nabika, T., Fujioka, A., Ohnaka, K., Asano, H., Yamori, Y., Yamaguchi, S., Kobayashi, S., Takayanagi, R., Ogihara, T., and Kato, N. (2010) Blood 
pressure and hypertension are associated with 7 loci in the Japanese population. Circulation 121, 2302-2309.

Tiranti, V., Rossi, E., Ruiz-Carrillo, A., Rossi, G., Rocchi, M., DiDonato, S., Zuffardi, O., and Zeviani, M. (1995) Chromosomal localization of mitochondrial transcription factor A (TCF6), single-stranded DNA-binding protein (SSBP), and endonuclease G (ENDOG), three human housekeeping genes involved in mitochondrial biogenesis. Genomics 25, 559-564.

Wang, Y., O'Connell, J.R., McArdle, P.F., Wade, J.B., Dorff, S.E., Shah, S.J., Shi, X., Pan, L., Rampersaud, E., Shen, H., Kim, J.D., Subramanya, A.R., Steinle, N.I., Parsa, A., Ober, C.C., Welling, P.A., Chakravarti, A., Weder, A.B., Cooper, R. S., Mitchell, B.D., Shuldiner, A.R., and Chang,
Y.P. (2009) From the Cover: Whole-genome association study identifies STK39 as a hypertension susceptibility gene. Proc. Natl. Acad. Sci. U. S. A. 106, 226-231.

WTCCC (2007). Genome-wide association study of 14,000 cases of seven common diseases and 3,000 shared controls. Nature 447, 661-678.

Yoshida, T., Biro, P., Cohen, T., Muller, R.M., and Shibahara, S. (1988). Human heme oxygenase cDNA and induction of its mRNA by hemin. Eur. J. Biochem. 171, 457-461.

Zhang, M., Zhang, B.H., Chen, L., and An, W. (2002). Overexpression of heme oxygenase-1 protects smooth muscle cells against oxidative injury and inhibits cell proliferation. Cell Res, 12, 123-132. 